\title{
Solid Organ Transplant Recipient
}

National Cancer Institute

\section{Source}

National Cancer Institute. Solid Organ Transplant Recipient. NCI Thesaurus. Code C130200.

An individual who is receiving a transplant of a solid organ. 